\title{
Linking Emissions Trading Schemes
}

\subsection{Introduction}

If the scientists are correct our World is on the edge of a precipice brought about by climate change. Every country, indeed, humanity faces an uncertain future. ${ }^{1}$

The great shame is that this has been understood for decades yet so little has been achieved to avert the dire predictions of climate change scientists. International agreement on the need to address anthropogenic emissions dates back to the early 1990s. In Rio de Janeiro, Brazil in 1992, 166 countries signed the United Nations Framework Convention on Climate Change ("UNFCCC") agreeing to work towards stabilizing greenhouse gas concentrations in the atmosphere. ${ }^{2}$ This Convention set no mandatory limits but in December 1997 the parties adopted the Kyoto Protocol, under which developed countries collectively committed to reduce greenhouse gas emissions by at least $5 \%$ below 1990 levels during 2008 to $2012 .{ }^{3}$ A core element of the Protocol was that a price should be set on greenhouse gas emissions as a primary means to achieve these reductions. ${ }^{4}$

The main mechanism to achieve this price was to be national emissions trading schemes ("ETS") that would be linked thereby establishing a global market. Funds would then flow to those entities and, indeed, jurisdictions that could generate or utilize clean energy most efficiently. The effect of both the internalization of the cost of carbon in commercial decisions and the opportunity to profit from a new industry focused on the generation of green energy and carbon elimination would drive behavior away from carbon emitting activities and, thereby, avert the worst predictions of climate change scientists.

International diplomacy, national politics, climate change skepticism and plain greed have all played their part in derailing the lofty ideals of both the Convention and its Protocol. As the Protocol's first period has drawn to a close, carbon emissions abatement has remained elusive. The Protocol has only been extended by virtue of a compromise in lieu of a new agreement as to carbon emission reduction

\footnotetext{
${ }^{1}$ It is not proposed to canvass the scientific debate in this paper. This has been performed admirably by others. For example, see Lidia Xynas, “Climate change mitigation: carbon tax - is it the better answer for Australia?” Australian Tax Forum 26 (2011): 339 - 347.

${ }^{2}$ www.unfccc.int (last visited 5 October 2012). There were 195 signatories as at that date. The December 2012 United Nations Climate Change Conference in Doha was the $18^{\text {th }}$ annual conference.

${ }^{3}$ The Protocol became available for signature by the parties to the UNFCCC from March 1998. The signing of the Protocol was largely symbolic - both the United States and Australia signed. However, under its terms it would not come into force until at least 55 (developed) nations comprising at least 55\% of the relevant emissions for 1990 ratified it. This quota was eventually met and it came into force on 16 February 2005.

${ }^{4}$ The Protocol envisages worldwide trading in carbon permits. Thus the Protocol established three market based mechanisms under which carbon permits might be effectively traded. Initially developed countries receive an assignment of units relative to their emissions "budget" (known as assigned amount units ("AAUs"). Developed countries are also granted removal units ("RMUs") in relation to domestic activities resulting in the net removal of greenhouse gases. RMUs and AAUs may be converted into emission reduction units ("ERUs"), the later through a "joint implementation project", namely a project that allows developed countries to work together by jointly implementing initiatives that reduce overall greenhouse gas emissions. Finally, there are certified emission reduction units ("CERS") generated from developed countries investing in projects that either reduce emissions or sequester carbon in sinks in developing countries, the so-called "clean development mechanism" designed to draw developing countries within the Protocol. CERs and ERUs can be used by countries to comply with their emission limitation targets under the Protocol or by operators of installations covered by domestic ETSs in order to meet their carbon emission obligations or can be assigned to other countries. See the useful New Zealand Government guide discussing these concepts at: http://www.eur.govt.nz/how-to/guides-hmtl/guide-to-kyoto-units-and-rules (last visited 5 October 2012).
} 
commitments. ${ }^{5}$ Meanwhile scientists increasingly warn of impending doom. For many we have passed the tipping point and the talk of a price on carbon is all too late. ${ }^{6}$

Amidst this gloom and unfulfilled promise have been some advances. Some countries have employed carbon taxes of varying levels of intensities. Most significantly, though, the European Union ("EU”) instigated an ETS back in 2005, New Zealand in 2008, Tokyo Metropolitan Government (“TMG”) in 2010, Australia in 2012 and California from 2013. In addition, a number of other countries and subnational entities have such regimes under contemplation.

With the advent of these regimes the opportunity for an embryonic trans-national carbon market emerges. The EU and former Australian Government had committed to partially link their regimes by 1 July 2014. ${ }^{7}$ Discussions were also held with New Zealand.

This paper outlines the principles relevant to the linking of ETSs concluding using the current Australian ETS to illustrate the issues that arise. First, the background to the current World environment supporting a fiscal response to climate change will be outlined.

\subsection{The international response to climate change}

The policy alternatives

Once it is accepted that manmade carbon emissions need to be reduced a number of Government initiated strategies are possible. First, there are regulatory measures ranging from prohibitions on the use of particular energy sources through to incentives to adopt more energy efficient practices and look to renewable energy solutions.

Another response is the adoption of fiscal measures which place a price on carbon emissions. For those countries that look to implement a carbon pricing mechanism, essentially there are two choices: a tax on carbon emissions or a market mechanism whereby a cap is placed on the amount of carbon that the country should emit (in line with its ultimate goal of achieving its Kyoto Protocol obligations) ${ }^{8}$ and permits to emit carbon can be traded. Under such a "cap and trade” system permits might be both issued by the Government and, effectively, created by entities trapping carbon.

The respective advantages and disadvantages of these alternative approaches have been the subject of much debate, one which it is not appropriate to engage in this paper. Suffice to say that a major deficiency in the carbon tax approach is the lack of a cap - conceivably the amount of carbon emissions could stay the same or even rise with the added cost simply passed on to consumers. The setting of the

\footnotetext{
5 “What Doha did”, The Economist (December 15, 2012) available at http://www.economist.com/news/international/21568355-no-progress-today-slightly-better-chance-progress-tomorrow-whatdoha-did (last visited 29 January 2013).

${ }^{6}$ Andrew Glikson, The Faustian bargain - while we debate the numbers, the planet suffers, The Conversation (online) (27 July 2011), available at http://the conversation.edu.au/the-faustian-bargain-while-we-debate-the-numbers-the-planet-suffers2512 (last visited 5 October 2012).

${ }^{7}$ At which date the proposal was that Australia would recognize EU credits, with full bilateral linkage from 1 July 2018.

${ }^{8}$ Generally see http://unfccc.int/2860.php (last visited 12 November 2012).
} 
tax rate (ie. the carbon price) would also be problematic for governments. Too low and nothing is achieved. Too high and the economy might be significantly damaged. ${ }^{9}$

Whilst a market based "cap and trade" scheme avoids these limitations such regimes suffer from the unknown and complexity. The negative impact on investment planning arising from the uncertainty as to the future carbon price, difficulties in fairly allocating carbon credits and the potential for speculation and corrupt market practices also have the potential to derail their effectiveness. ${ }^{10}$

In the absence of a global co-ordinated regime either mechanism has to deal with the international environment. A central concern is the potential for fiscal measures to drive industry offshore to escape the competitive disadvantage generated by the added cost burden. In carbon pricing parlance the expression "carbon leakage" has been coined to refer to the phenomenon where origin based carbon pricing leads to a reorientation of carbon emitting activities away from countries that price carbon to destinations that do not.

The typical policy response is to introduce a border adjustment tax that seeks to tax the underlying amount of carbon emissions reflected in imports from destinations without pricing mechanisms. ${ }^{11}$ Apart from the obvious difficulties in setting the rate of tax and identifying the amount of indirect carbon emissions there is a concern that such taxes may violate international trade rules, and, in particular, the General Agreement on Tariffs and Trade (the "GATT"). ${ }^{12}$ For an ETS a further issue is as to whether and what permits issued by foreign countries should be recognized. If foreign carbon markets are not available to domestic entities then a higher domestic market price compared to other countries (as would be expected if other markets were larger) might lead to carbon leakage. Recognizing foreign permits exposes the country to integrity issues which might be problematic for its carbon regulator to resolve.

\section{The international framework}

As noted in the introduction, pursuant to the UNFCCC and its Protocol developed countries have committed to reducing their greenhouse gas emissions. The use of fiscal measures is identified as a primary measure to achieve these reductions.

Notwithstanding high ideals and pressing calls for global action some countries, in particular the United States and Australia, held out ratifying the Kyoto Protocol. Political disagreement stemmed primarily from the potential unfair competition for high emission industries of committed nations that might flow from the decision to exempt developing nations. The notion that border adjustments, in the nature of a carbon charge on imports from non-committing nations and, possibly also an exemption for exports to such nations from the domestic carbon price, might level the playing field was met with both a realization as to the administrative complexity of such measures and the uncertainty as to whether they

\footnotetext{
${ }^{9}$ For a discussion of the difficulties of setting a carbon tax rate and a possible solution see: Etienne Billette de Villemeur and Justin Leroux, “CO2: Tax now, Pay later!” 66 Tax Notes International 49 (April 2, 2012).

${ }^{10}$ Lidia Xynas comprehensively canvasses the opposing arguments in relation to carbon taxes and emission trading schemes concluding that a carbon tax is preferable: Xynas, "Climate change mitigation: carbon tax - is it the better answer for Australia?”, 352 - 370. For a similar conclusion see Jim Corkery, “A carbon tax - onwards” (2009) 19(1) Revenue Law Journal 7, 1.

${ }^{11}$ An alternative response is the issuing of free carbon permits to trade exposed industries, which presents its own difficulties as a policy solution.

${ }^{12}$ An alternative might be to encourage non-abating exporting countries to impose a carbon tax on their exports, encouraged by the realization of an additional revenue flow that might otherwise go to abating countries in the form of border adjustments.
} 
would withstand scrutiny under the GATT. ${ }^{13}$ Nevertheless, with Australia eventually ratifying the Protocol in December 2007, the United States remained as the only signatory that had not ratified. ${ }^{14}$

Working alongside the Kyoto Protocol have been the United Nations climate change conferences. As at the time of writing the World has met for 18 climate change conferences. The 2009 Copenhagen conference was to be a watershed in ensuring a global framework for climate change mitigation. However the conference achieved little other than recognition of the damage that a greater than 2 degree Celsius increase in World temperatures would cause. ${ }^{15}$ Since the 2010 session at Cancun (Mexico) though, countries have begun pledging to limit or reduce their emissions. At the time of writing around 90 such pledges have been made, comprising countries responsible for more than $80 \%$ of greenhouse gas emissions. Such pledges may not be legally binding but, in reality, neither is commitments made under the Protocol given the absence of any true enforcement mechanism. The real significance of the pledges is the affirmation by the countries concerned of their political will to take steps to reduce greenhouse gas emissions irrespective of any international agreement. ${ }^{16}$

The Kyoto Protocol and the climate change conferences have acknowledged that government responses to climate change can vary. However, whilst regulation, subsidies and direct government action may be part of the solution, ${ }^{17}$ placing a price on emissions is regarded as the most cost effective measure, whether achieved through a cap and trade market mechanism or employing a carbon tax. ${ }^{18}$ The Protocol acknowledges the advantage of the former that it can be set to achieve emission reductions with these reductions phased in over time as less permits are made available (ie. the cap is reduced). Where schemes can be linked internationally then economies of scale might be achievable with a more cost effective transition to lower emissions. ${ }^{19}$

Since 2005 the 27 countries comprising the EU (and four non-members) ${ }^{20}$ have had an ETS in place that has been gradually extended to cover around $40 \%$ of EU emissions. ${ }^{21}$ New Zealand established a scheme

\footnotetext{
${ }^{13}$ See the discussion in Charles E. McLure Jr., "Border adjustments for carbon taxes and the cost of CO2 emission permits: politics, economics, administration and international trade rules” Bulletin for International Taxation 585 (November 2010 ).

${ }^{14}$ Although Canada subsequently withdrew its ratification in 2011: Jonathan Hayward, "Canada first nation to withdraw from Kyoto Protocol” thestar.com (12 December 2011) available at

http://www.thestar.com/news/canada/politics/article/1100802--canada-withdrawing-from-kyoto?bn=1\#article (last visited 5 October 2012).

${ }^{15}$ John M. Border, “Many goals remain unmet in 5 nations’ climate deal” The New York Times (online), 18 December 2009 available at www.Nytimes.com/2009/12/19/science/earth/19climate (last visited 5 October 2012).

${ }^{16}$ Daniel Bodansky, "W[h]ither the Kyoto Protocol? Durban and beyond." Policy Brief, Harvard Project on Climate Agreements, Belfer Center for Science and International Affairs, Harvard Kennedy School, August 2011, available at http://belfercenter.ksg.harvard.edu/publication/21314/whither the kyoto_protocol_durban_and beyond.html (last visited 15 October 2012).

${ }^{17}$ Especially focusing on encouraging the adoption of sources of renewable energy and embracing strategies to achieve energy efficiency.

${ }^{18}$ See, for example, the OECD report, Taxation, Innovation and the Environment available at www.oecd.org/document/6/0,3746,en_2649_34281_46091974_1_1_1_1,00.html (last visited 5 October 2012).

${ }^{19}$ Originally the aim was to have an international ETS but after protracted negotiations the establishment of national domestic regimes was seen as the way forward: Wolfgang Sterk and Ralf Schule, "Advancing the climate regime through linking domestic emission trading systems?” (2009) 14 Mitigation and Adaption Strategies for Global Change 409 Wuppertal Institute for Climate, Environment and Energy, Germany (“Sterk 2009”) available at http://ideas.repec.org/a/spr/masfgc/v14y2009i5p409-431.html (last visited 4 March 2013).

${ }^{20}$ The European Economic Area European Free Trade Association States (Iceland, Liechtenstein and Norway) adopted the EU legislation from 2008. Norway had a pre-existing ETS which was effectively replaced by the EU regime with some modifications and so was not a linking of two regimes in the true sense: see

http://www.icao.int/Meetings/EnvironmentalWorkshops/Documents/WACM-2008/3_Svarstad.pdf;
} 
in 2008 initially covering only forestry but broadened significantly in 2010. ${ }^{22}$ Since 1 July 2012 Australia has had a broad ranging ETS in operation. ${ }^{23}$ The Australian Climate Commission had reported an expectation that carbon pricing schemes would be operating in at least 33 countries and 18 states by the end of 2013. This included seven cities and provinces in China ${ }^{24}$ and California, the World's ninth largest economy. ${ }^{25}$ The Republic of Korea has also passed legislation for an ETS to start from 1 January 2015 as part of its ambition to become the world's seventh largest green economic power by $2020 .^{26}$ Meanwhile other countries have adopted carbon taxes as their approach to pricing carbon. ${ }^{27}$

\section{Linking and its advantages (and disadvantages)}

With the gradual introduction of these national and sub-national ETSs the possibility of linkages emerges. ${ }^{28}$ The prime advantage of linking two regimes is to create a larger market that would see price fluctuations dampened and the influence of speculators and market manipulation reduced. The price signal might also be more credible in the sense that linking suggests that a domestic ETS is a long-term commitment less prone to the lure of short-term discretionary domestic policy. Greater price certainty would be more amenable to commercial activity. ${ }^{29}$

A larger and more diversified market should also provide greater opportunities for credit acquisition and emissions abatement and assert downwards pressure on the carbon price leading to a more cost effective emissions reduction outcome. Funds would flow to those jurisdictions with a lower cost of abatement (ie. had most effectively reduced their carbon emissions below their targets and so were characterized by

http://www.bellona.org/articles/articles_2007/norway_emissions_trading_system and the EEA Joint Committee Decision No $146 / 2007$ available at

http://eur-lex.europa.eu/LexUriServ/LexUriServ.do?uri=CELEX:22007D0146:EN:NOT (all last visited 2 April 2013). Since 1 January 2013 the EU regime has also applied to Croatia which is to become a EU State in July. Switzerland proposes to link its domestic ETS with the EU regime from 2014.

${ }^{21}$ The EU has also canvassed the idea of introducing a carbon tax to apply to activities outside the scope of its ETS: Charles Gnaedinger, "EU finance ministers study carbon tax" 56 Tax Notes International 105 (Oct 12, 2009).

${ }^{22}$ For a comparison of the Australian and New Zealand regimes see Joanne Dunne, "Emissions trading and tax: a transTasman perspective” (2012) 47(3) Taxation in Australia 157. The United Kingdom has also had a form of ETS operating since 2002.

${ }^{23}$ A new Coalition Government elected in September 2013 has tabled draft legislation repealing the current ETS effective 1 July 2014 prior to the trading mechanism commencing and the proposed link with the EU.

${ }^{24}$ A national pricing scheme is also under consideration: Randall Jackson, "Carbon tax planned for 2015" 65 Tax Notes International 179 (Jan 16, 2012).

${ }^{25}$ The Californian scheme is anticipated to link with that of Quebec pursuant to the Western Climate Initiative.

${ }^{26}$ Randall Jackson, "National Assembly passes carbon emissions trading scheme” 66 Tax Notes International 610 (May 14, 2012). Whilst the arrangements will target $60 \%$ of the country's greenhouse gas emissions in the first five years, at least, entities affected will be allotted $95 \%$ of their emission credits.

${ }^{27}$ Finland introduced the world's first carbon tax in 1990 followed by other Scandinavian countries. South Africa has plans for a carbon tax from 2013: Randall Jackson, "Budget proposals include carbon tax, relief measures" 65 Tax Notes International 666 (Feb 27, 2012).

${ }^{28}$ Both TMG and Australia are members of the International Carbon Action Partnership ("ICAP"). ICAP is an open forum comprised of public authorities and governments that have established or are actively pursuing carbon markets through mandatory cap and trade systems with absolute caps. It provides a forum to share experiences and knowledge especially with a view to facilitating future linkages. Japan is an observer. See http://www.icapcarbonaction.com/ (last visited 13 November 2012).

${ }^{29}$ OECD Environment Directorate and International Energy Agency, Towards international emissions trading: design implications for linkages, Information Paper, OECD 2002 (“OECD 2002”) available at

http://www.oecd.org/environment/climatechange/2766158.pdf (last visited 4 March 2013) and see R. B. Dellink, S. Jamet, J. Chateau and R. Duval, Towards global carbon pricing: direct and indirect linking to carbon markets, OECD Environment Working Paper 2010 available at http://www.oecd-ilibrary.org/environment/towards-global-carbon-pricing_5km975t0cfr8-en (last visited 3 March 2013). 
excess credits) so favouring and supporting such jurisdictions and leading to a more efficient allocation of resources. The World would become greener, cheaper.

In addition to the economic case for linking some political advantages are also envisioned. Enhanced cost effectiveness and the ability to point to international partners might render stricter domestic targets more acceptable and linking would help avoid the problem of leakage. Also a bottom up approach of linking domestic regimes might serve to complement the Kyoto top down approach as well as provide a fallback structure to the Kyoto regime. Finally, if countries with ETSs link then this both sends a message of approval to linkage partners and also one that might help to engage the big polluting countries, especially the USA. ${ }^{30}$

The case for linkage focuses primarily on the global benefits. One perceived disadvantage of linking though is that the reduction in the price and the purchase of foreign credits may result in lower emissions reductions in a given jurisdiction, although globally the reductions exist. For this reason a jurisdiction may seek to compromise the desire to be part of a larger market, with its advantages, with a cap on the amount of foreign credits that may be claimed, thereby ensuring some level of local reductions.

Whilst the preponderance of views supports the case for linking some commentators have expressed caution. In particular, they point to the potential to import price volatility from a linkage partner and the potential negative distributional consequences for a jurisdiction. The later includes not only the potential for wealth to flow to other jurisdictions with lower marginal costs of abatement but also the loss of ancillary benefits that might come from domestic emissions abatement (rather than the purchase of foreign credits), such as reduced local pollution, increased energy security, encouragement of R\&D and general economic stimulus. Furthermore, for a particular jurisdiction not all potential linkage partners may be welfare enhancing. Some may seek to adjust national caps and game the linkage. Domestic policy objectives may be compromised by the effect of those of the linked jurisdiction, especially where there are different priorities given to cost containment over environmental effectiveness. There is also likely to be some loss of control over the domestic regime arising from the need to accommodate the views of the linkage partner.

Ultimately, the decision whether to link is a political one requiring the identification of, and a trade off between, the various advantages and disadvantages. ${ }^{31}$

\subsection{Principles for linking ETSs}

Links might be unilateral, bilateral or multilateral. Furthermore, an ETS may link with another either directly or indirectly. The later can occur where two ETSs approve the use and trade of CERs and ERUs. ${ }^{32}$ In such case the international market for these allowances extends to and influences the carbon price in both markets. Thus if a higher carbon price in one jurisdiction was to lead to the purchase of CERs on the international market resulting in their scarcity then this will contribute to pushing up the

\footnotetext{
${ }^{30}$ See Sterk 2009 for a comprehensive statement of the advantages of linking, including political benefits: at $411-412$.

${ }^{31}$ Generally see Christian Flachsland, Robert Marschinski and Ottmar Edenhofer, "To link or not to link: benefits and disadvantages of linking cap-and-trade systems” (2009) 9 Climate Policy 358. The authors generate a useful table (Table 2) summarizing the potential advantages and disadvantages of linking.

32 These concepts are defined in footnote 4.
} 
carbon price in that other market. Furthermore, indirect linkage may occur where direct trading between two regimes is conducted through a clearing house, which might be necessary to counteract differences between the two systems (such as methods of calculation). ${ }^{33}$

As observed above, whilst linking is generally advantageous, issues can arise with linkages where the environmental objectives within one ETS are pursued with less stringency thereby impacting on the achievement of the environmental objectives of the other regime. In a less stringent regime the price is likely to be lowered reducing the incentive to innovate and reduce emissions: cost containment is weighted more heavily over environmental effectiveness. The effect on market functionality and the relative competitiveness of entities operating under each regime are also considerations relevant to linking, although whilst differences can lead to competitiveness distortions these will arise in any event regardless of whether the regimes are linked. Significantly, most commentators suggest that few design characteristics of an ETS are critical to whether systems may be linked, as distinct from whether they should be.

The critical design issues in establishing an ETS and their implications for linking compatibility are considered below, ${ }^{34}$ roughly in order of significance. ${ }^{35}$

\section{Intensity $v$ absolute targets}

An ETS may mandate that entities not exceed targets expressed as emissions per unit of output or activity or even per unit of input. These are known as intensity or relative targets. One limitation of such targets is that emissions may continue to increase as a result of increases in activity. They are thus more liberal than absolute targets, although in both cases the stringency of the targets is a critical consideration. Typically absolute targets are set by reference to the historical emissions ("grandfathering”) with a reduction factor applied or "benchmarking”.

Whilst it may be possible to link intensity based and absolute target ETSs, ${ }^{36}$ equity concerns may arise due to the more liberal nature of intensity targets. Also an intensity based regime may impact on the environmental effectiveness of the combined regimes as output increases will increase the number of allowances available. Furthermore, as under an intensity regime allocations may be given out only once the current output data is known (and not in advance as with absolute targets) this could result in a

\footnotetext{
33 Such a clearing house can also be used as a means of controlling or decoupling the link between the two regimes: Alexander RoBnagel, "Evaluating links between emissions trading schemes: an analytical framework”, (2008) Carbon and Climate Law Review 394 at 397 ("RoBnagel 2008”).

${ }^{34}$ Generally see OECD 2002, Sterk 2009, RoBnagel 2008, Jane Ellis and Dennis Tirpak, Linking GHG emission trading schemes and markets, OECD 2006 (“OECD 2006”) available at

http://www.oecd.org/env/climatechange/greenhousegasemissionstrading.htm (last visited 1 March 2013), William Blyth and Martina Bosi, Linking non-EU domestic emissions trading schemes with the EU emissions trading schemes, OECD 2004 (“OECD 2004”) available at http://www.oecd.org/env/cc/32181382.pdf (last visited 3 March 2013) and M. J. Mace, Ilona Millar, Christoph Schwarte, Jason Anderson, Derik Broekhoff, Robert Bradley, Catherine Bowyer and Robert Heilmayr, Analysis of the legal and organizational issues arising in linking the EU emissions trading scheme to other existing and emerging emissions trading schemes, European Commission, May 2008 ("Mace 2008”) available at http://www.field.org.uk/files/Linking\%20emission\%20trading\%20schemes_0.pdf (last visited 1 March 2013).

${ }^{35}$ Whilst the discussion of the views of current linkage parties and the need for Kyoto Protocol compliance appear at the end of this section in a given situation these considerations may be much more significant.

36 Technical fixes may be necessary: see OECD 2004 at paragraph 2.3.
} 
liquidity shock for the absolute scheme at the moment of adjustment. Notably the EU has ruled out linking its ETS with schemes based on intensity targets. ${ }^{37}$

One circumstance where linkage to an intensity based regime may be less of a concern is if the regime is that of a Kyoto ratifying country where an overall national cap is imposed on emissions and the allowances of the national ETS are shadowed by and/or convertible to Kyoto units. In such circumstances, there should not be any environmental compromise associated with linking since increased emissions will need to be offset elsewhere in the economy, or through purchase of Kyoto units. $^{38}$

\section{Ex-post adjustments of allowances}

Emissions limits are specified over a period usually described as the "commitment period". They are typically established at the start of that period. Systems which allow for subsequent adjustments as a price controlling measure are unlikely to be attractive as linkage partners. Such a measure could enable politically-motivated market influence and undermine the market. ${ }^{39}$ Any system which contains such a measure that detracts from the free rein of market forces would reduce the environmental integrity of any other system to which it was linked.

\section{Market interventions and price caps}

Aside from adjusting allowances, market intervention is conceivable through other, possibly more subtle, measures. Differing views exist as to whether these mechanisms should be built into an ETS. Some view a system where the market dynamics are free to operate as preferable whilst others prefer the government to be able to step in as an emergency measure to correct market imperfections, such as those caused by speculative practices. Where systems are linked then if one permits market interventions the effect will be to apply to both systems. This may form a barrier to linking ${ }^{40}$ although the very fact of linking and expanding the market can reduce the risk of speculation and price spikes.

In particular, if an ETS without a price cap is linked to one with a cap (or other cost containment measures), ${ }^{41}$ the cap will effectively establish the compliance cost for both regimes. Where the allowance price (in the non-capped jurisdiction) is above the price cap entities operating under the ETS without the cap will purchase allowances from entities operating under the ETS with the cap undermining the environmental integrity of the two schemes. The extent to which the price cap (or other cost containment measures) may discourage linking depends upon how much the price cap (or trigger price) approximates the expected marginal abatement costs. Less concern may arise if the price is set so high as to amount to a true emergency measure only.

\footnotetext{
${ }^{37}$ Hitomi Kimura and Andreas Tuerk, Emerging Japanese emissions trading schemes and prospects for linking, Climate Strategies October 2008 (“Kimura and Tuerk 2008”) available at www.climatestrategies.org (last visited 5 November 2012). Also see OECD 2002 at paragraph 3.5. At sub-paragraph 3.5.5 the OECD outlines a gateway mechanism that might be utilized to prevent transfers to the absolute sector that would impact on the environmental effectiveness of that sector.

${ }^{38}$ OECD 2004 at paragraph 2.3.

${ }^{39}$ Mace 2008 at paragraph 3.4.4.

${ }^{40}$ See the grounds for the pessimistic conclusion by Michael Mehling in the briefing document to the European Parliament: Linking the EU emissions trading system to a future US emissions trading scheme, 2009 available at www.europarl.europa.eu/activities/committees/studies.do?language=EN (last visited 28 February 2013).

${ }^{41}$ Such as "strategic allowance reserves" of emissions credits which might be released should the price climb too high (also known as safety valves or circuit breakers).
} 
It can be expected that this may be an ongoing issue as new ETSs emerge, especially those with a broad coverage and that are likely to be price takers in a larger market. Governments are likely to require their regimes to display a large degree of regulatory certainty and price stability and predictability, at least in their early years, to garner political support. Thus cost containment measures, such as price caps or offset credit provisions, may have a higher priority than ensuring that the regime is designed with linkage in mind. ${ }^{42}$ The ultimate question for any prospective linkage partner will be whether the measure is intended to be readily employed for cost containment purposes or only in emergencies as a last resort.

\section{Banking, borrowing and the commitment and compliance periods}

Where an ETS allows an entity to retain allowances to be offset against its emissions obligations of a future period this is known as banking. This is not problematic where it reflects mitigation methods or excess purchases over needs (rather than over-allocation of free allowances). However differences in the stringency of banking rules can lead to competitive advantages in favour of entities operating in the less stringent regime.

Borrowing means that an entity is allowed to use allowances expected to be granted in a future period to cover current emissions. Borrowing may be problematic for the integrity of an ETS because it might encourage lobbying for a relaxation of future targets by entities that have borrowed and poses the risk that such entities may terminate their activities after having utilized their future allowances. Thus an ETS that allows borrowing is less attractive as a linkage partner given the risk of weakening the environmental effectiveness of the partner scheme. ${ }^{43}$

Not only is it preferable that the rules on banking and borrowing be consistent across two linked schemes but the same considerations mandate that the period over which there is a commitment to reduce emissions and any compliance or trading intervals within this period should be the same. ${ }^{44}$ Where there are discrepancies in these rules across linked schemes the effectiveness of the scheme with the more stringent rules will be reduced because it would be possible to sidestep any prohibitions on banking or borrowing. For example, excess allowances (that may not be banked) might be sold in the other scheme whilst borrowed allowances might be sold across to entities in a jurisdiction where borrowing is prohibited. Jurisdictions might also be tempted to "game the system" to use a new commitment period to impose less stringent obligations on domestic entities and thereby favour the entities in their jurisdiction by enhancing their potential to have excess allowances for sale. ${ }^{45}$

\section{Target stringency}

The relative stringencies of targets adopted by the schemes and their enforcement are a further linkage consideration. If caps are not comparable then the less stringent regime will have the effect of impacting

\footnotetext{
${ }^{42}$ Tuerk et al (2009). The existence of a price cap in Australia’s 2008 version of an ETS was argued as a major obstacle to linking: Frank Jotzo and Regina Betz, “Australia’s emissions trading scheme: opportunities and obstacles for linking” (2009) 9 Climate Policy 402.

${ }^{43}$ Although systems may be put in place to mitigate concerns: see OECD 2002 at paragraph 3.6 and sub-paragraph 3.6 .3 in particular.

${ }^{44}$ Although others have argued that different trading periods can be beneficial as they improve market liquidity: W. Sterk, M. C. Braun, K. Korytarova and A. Scholten, "Ready to link up? Implications of design differences for linking emissions trading schemes”, 2006 Jet-Set working paper I/06, Wuppertal Institute, Wuppertal, Germany.

${ }^{45}$ Mace 2008 at paragraph 3.5.4.
} 
on the environmental effectiveness of the other scheme and lead to a wealth transfer to the more lenient country where excess credits are likely to have been generated.

However, it should be observed that it is not so much the level of the emissions target in each jurisdiction that is relevant to the capacity to link but rather the relative shortage of emissions allowances that it creates and hence the extent of the incentive to reduce emissions. Where two systems are linked and the reduction pressure in one jurisdiction is lower than the other then it could be expected that the two will converge leading to a reduction in the likelihood of achieving the environmental objectives of that jurisdiction imposing the greatest cuts.

Other aspects related to the target, such as the setting mechanism and whether it is a static or dynamic (ie. able to change pursuant to a set model), are relevant and some agreement should preferably be reached prior to linking. Certainly such differences will have an impact on the operation of each of the opposing systems although none should be fatal to linkage. Rather the critical consideration is the level of ambition rather than the actual features of the target cap.

\section{Limits on the purchase of foreign allowances}

The rationale for linkage is to establish a larger market for emissions allowances thereby reducing the possibility of wild price fluctuations and promoting efficiencies. Thus, if entities in one linked jurisdiction have excess allowances due to the more widespread adoption of clean energy then they will be able to sell these, thereby lowering the global price.

On the other hand, complete reliance on cheap allowances sourced from a linked jurisdiction will dampen the incentive effect in a particular jurisdiction to reduce domestic emissions (albeit global emissions are down). So there is a tradeoff and some jurisdictions may seek to design their ETS to place a limit on the amount of foreign and/or Kyoto credits that might be used to cover an emissions obligation. ${ }^{46}$ However restrictions of this sort imposed by one regime and not others may generate inconsistent treatment of competitive industries across the linked markets.

\section{Indirect linking and project based credits/offsets}

Linking to one system has the effect of indirectly linking to all systems to which it is linked. Thus if one system recognizes CERs from CDMs and/or ERUs from JIs and another does not (or limits the use of such credits) ${ }^{47}$ then this will impact on the innovation incentive of that other system. ${ }^{48}$ Entities in the system with the restrictions might enter into swap arrangements effectively converting any non-allowed credits into allowed ones. This issue, though, would not affect the World market where the same

\footnotetext{
${ }^{46}$ One justification for limiting the availability of Kyoto units to satisfy domestic ETS obligations is the existence of "hot air" permits which arose from the excessive allocation of units to former Eastern Bloc countries prior to the massive reduction in emissions experienced by them in the 1990s. See the discussion in Frank Jotzo and Regina Betz, “Australia’s emissions trading scheme: opportunities and obstacles for linking” (2009) 9 Climate Policy 402.

47 See footnote 4 for an explanation of these terms.

48 Thus making linkage less attractive to the more stringent regime: see Michael Mehling in the briefing document to the European Parliament: Linking the EU emissions trading system to a future US emissions trading scheme, 2009 available at www.europarl.europa.eu/activities/committees/studies.do?language=EN (last visited 28 February 2013). Also see the concerns with Australia’s 2008 version of an ETS: Frank Jotzo and Regina Betz, “Australia’s emissions trading scheme: opportunities and obstacles for linking” (2009) 9 Climate Policy 402.
} 
incentive to reduce emissions will remain. It would purely allow for the rules of a particular ETS to be side stepped.

Furthermore, where domestic regimes give rise to offsets or allowances then any prospective linkage partner will wish to ensure that the monitoring and verification procedures embedded in these regimes are sufficiently rigorous and comparable. ${ }^{49}$ Some uniformity in the rules as to the recognition of offsets and allowances is, therefore, preferred, although if domestic offsets and allowances are shadowed by and/or convertible to a Kyoto unit (and hence satisfy the Kyoto framework for recognition) then this fact alone is likely to provide sufficient endorsement to accommodate any linkage concerns. ${ }^{50}$

\section{Mandatory versus voluntary}

ETSs can be designed to be either mandatory regimes or voluntary. Voluntary regimes can vary in terms of their "voluntariness" where incentives for remaining in the scheme, penalties for leaving and other social pressures have an application.

Depending on how truly voluntary a regime is there may be adverse implications for any linked mandatory scheme. Allowance prices tend to be lower in voluntary schemes both contributing to and reflecting the lower innovative pressure and lower incentive to reduce emissions. Competitive distortions can occur between entities in the two regimes and the functionality of the combined systems each time market forces take effect causing participants to depart the voluntary system. Competitiveness issues also arise where incentives are provided to encourage entities to join the voluntary scheme. ${ }^{51}$

\section{Non-compliance provisions, sanctions and countervailing incentives}

An ETS with rigorous non-compliance provisions, such as high penalties, and effective governance and enforcement might be reluctant to link with an ETS with a less stringent regime. If the penalties imposed by one regime are lower or poorly enforced then linkage will encourage non-compliance in that program with the allowances sold to entities operating in the other regime. That is, non-compliance would be exported to the country with the weakest penalty regime. ${ }^{52}$ Where a penalty absolves an entity from the obligation to cover its emissions with allowances then the penalty effectively acts as a price cap. As discussed above, the presence of such a price cap can compromise the environmental integrity of both regimes.

A related issue may be the respective income and consumption tax treatment of gains and losses from trading in the respective jurisdictions. For example, it is conceivable that if one jurisdiction exempts ETS trading gains and/or transactions from taxation and the other does not then this could impact on achievement of the environmental objectives of the taxing regime as an incentive might exist for entities in the non-taxing regime to sell their allowances across. ${ }^{53}$ Pressures on price distortions across the two

\footnotetext{
${ }^{49}$ Mace 2008 at paragraph 3.5.5.

${ }^{50}$ OECD 2004 at paragraph 2.2 .

${ }^{51}$ OECD 2002 at sub-paragraph 3.7.1.

${ }^{52}$ OECD 2002 at sub-paragraph 3.7.2.

53 There are numerous variables that could complicate this analysis such as the residency for tax purposes of the entities involved, the source attributed to any gain, whether the tax regimes of the respective jurisdictions are global or territorial and the application of any double tax treaty between them.
} 
regimes are also a possibility from inconsistent taxation regimes. Certainly inequities across the regimes would be created, although these would exist irrespective of linkage.

Similarly, if one jurisdiction has additional taxes and imposts on emissions then these will also influence the carbon price in both jurisdictions. Conversely, where one jurisdiction has in place countervailing incentives, such as subsidies or tax abatements for emitting production or consumption then this will impact on the incentive to reduce emissions in the linked jurisdiction. Such incentives should be either replicated in all linked jurisdictions or eliminated. ${ }^{54}$

\section{Monitoring, verification and reporting}

It is critical to the integrity of an ETS that it contains an emissions reporting obligation that is effectively monitored and audited for verification. Verification is also important in the context of the credits/offsets that are available.

If the design features of each linked ETS in terms of monitoring, verification and reporting vary markedly (in terms of stringency if not detail) then across the schemes the incentive to reduce emissions and pressure to innovate will converge at the level of the least robust scheme. ${ }^{55}$ Each system needs to be designed so that avoidance opportunities are minimized (for example, all emitting sources of a particular participant are caught) and emissions need to be fully and reliably measured. The verification authority needs to be independent and reliable. If under one regime less stringent verification is a feature then it may be less attractive as a linkage partner. The other partner may require additional verification activities, typically using the services of an independent entity, before recognizing cross border allowances or credits/offsets.

Less important from a linkage perspective are the difference in the scope and method of the reports and, even, whether allowance or unit rights are identical as differences in the rights attached to allowances might be resolved using a clearing house intermediary. ${ }^{56}$

\section{Upstream versus downstream application}

The designers of an ETS must decide upon whom to impose the requirement to account for emissions through the purchase of allowances. There is a spectrum of possibilities from imposition on producers and importers of fuels, to those using the fuels to create energy and emitting greenhouse gases (primarily the energy suppliers and some manufacturers - making direct emissions accountable) through to where the ultimate consumer of a product or service may have to account for the indirect emissions embedded in the item or service (distinguished as upstream or downstream approaches). ${ }^{57}$ From a theoretical perspective the incentive effect away from emissions intensive activities should be the same as under either approach the ultimate consumer would be paying for the price on carbon, in the upstream

\footnotetext{
${ }^{54}$ Robnagel 2008 at 399 (fn 31).

55 Although efforts have been made to standardize these rules: see The Greenhouse Gas Protocol - a corporate accounting and reporting standard (WBCSD/WRI, 2001).

56 See footnote 33.

57 The OECD 2002 report describes an approach that caps emissions at the emissions level as "direct" and one where the ultimate consumers are held accountable for the emissions embedded in the goods or services they consume as "indirect": see paragraph 3.3. However described the issue remains that linking is, nevertheless, achievable although systems would need to be implemented to ensure no regulatory gaps or double jeopardy.
} 
approach the carbon price is reflected in the price of the fuel, energy, item or service. However the potentially wider coverage and administrative and compliance cost advantages of an upstream approach render it more attractive.

It is possible that double jeopardy or regulatory gaps may emerge where trade occurs between two jurisdictions with differing approaches. For example, a gap may occur where one regime has an upstream application and the other downstream and an entity in the downstream regime sells goods to consumers in the upstream jurisdiction. This is not necessarily a consideration relating to the linkage of the two carbon markets but more as to the integrity of the two regimes and the significance of some form of border adjustment mechanism. Thus this factor should not impact on the ability to link two schemes. ${ }^{58}$

\section{Sector and gas coverage}

A further design issue with an ETS is as to what sectors or categories of emissions and to what gases it should apply. As a general principle, the more sectors and gases that are covered the greater the potential for market efficiency and lower compliance costs. ${ }^{59}$ Linking schemes that apply to different sources of greenhouse gases or, indeed, different gases should be achievable and actually increase opportunities for abatement and reduce costs. Each regime would, however, need a common transaction unit and adequate monitoring and verification regimes. ${ }^{60}$

\section{Free allocation versus auctioning}

Essentially two methods can be adopted to allocate allowances. A government might sell them through a competitive auctioning process or allowances could be allocated free of charge in proportion to the entity's past emissions (grandfathering). In the case of grandfathering an optional feature is for each entity's allocation proportion of the total allowances to be adjusted up or down in the next period on the basis of an increase or decrease in its activity level (updating).

The allocation method needs to be such as to not affect the legitimacy of the system as a whole. The possibility of windfall profits to market participants is a risk with free (over) allocation. In the case of an auctioning system care must be taken to ensure that the auctions operate with market efficiency and integrity in mind. In particular, competitive or collusive conduct by bidders at an auction must be avoided. ${ }^{61}$ Auctioning in one jurisdiction where the allowances are freely allocated in another can lead to wealth distribution and competitive distortions between competing enterprises. However linking is unlikely to worsen the situation. ${ }^{62}$

\section{Compatibility of registries}

\footnotetext{
58 See RoBnagel (2008) who discusses the significance of the alternative approaches in some detail. Also see OECD 2002 at paragraph 3.2 .

${ }^{59}$ In the sense that the costs of abatement or allowances should be reduced with a wider coverage.

${ }^{60}$ OECD 2002 at paragraph 3.4.

${ }^{61}$ Mace 2008 at paragraph 3.7.1. Also see M. J. Mace and J. Anderson, “Transnational aspects of a linked carbon market”, (2008) 2 Carbon and Climate Review 190.

${ }^{6}$ OECD 2002 at paragraph 3.1.
} 
Compatibility of registries and the trading platform is important to ensure the functionality of the linked systems. Preferably they should be capable of online linkage. To some extent differences may be ameliorated by the use of an intermediary clearing house. ${ }^{63}$

\section{Kyoto Protocol compliance}

Countries that remain signatories to the Kyoto Protocol will wish to ensure that any allowances acquired from a foreign source are backed by Kyoto units which can then count towards the country's international emissions reduction obligations. ${ }^{64}$ This could be problematic where a potential linkage partner is not a member of the Kyoto framework (or their ETS does not comply with Kyoto principles) or where it is a sub-national entity which might not be able to effect a transfer of national Kyoto units. In such circumstances, though, a gateway mechanism, which provided a procedure to ensure that transfers from outside the Kyoto framework have Kyoto allowances attached, might facilitate the creation of a linkage. Such a mechanism would also ensure that where transfers are made to entities outside the framework any attached Kyoto allowances are captured and not used inappropriately. ${ }^{65}$

Linkage to an ETS in a developing country which has no national emissions cap could also potentially contribute to a form of carbon leakage. ${ }^{66}$

\section{Views of existing linkage partners}

Linking to a new jurisdiction has flow on implications for any existing linkage partners. The ambition reflected by the combined schemes will settle at the level of the least stringent scheme. Issues of environmental integrity and wealth distribution will be impacted in all linked schemes by the addition of a further partner. For this reason it would be expected that any linkage agreement would contain provisions requiring the agreement of existing linkage partners to the linking of another jurisdiction.

It may also be the case that a new bilateral linkage agreement would need to be formed between any new partner and each of the pre-existing linked jurisdictions. Alternatively, it might be that the addition of a partner would be an opportunity to convert a bilateral linkage agreement into a multi-lateral agreement if the framework of the former does not readily permit the addition of another partner. Regardless of the mechanics of the arrangement the critical point is that linking will result in some loss of sovereignty over future decisions in relation to a jurisdiction's ETS and, in particular, as to future linkage partners.

\subsection{The mechanics of linking}

Whilst a detailed consideration is outside the scope of this paper, ${ }^{67}$ once the decision is made to link two systems it will be necessary to establish the legal framework to achieve the linkage. Bilateral linkage might be achieved through either an international treaty or through reciprocal domestic legislation

\footnotetext{
63 See footnote 33.

${ }^{64}$ Linking to or between systems outside the Kyoto Protocol is feasible although not contributing to a negotiation of a global burden sharing regime: see Andreas Tuerk, Michael Mehling, Christian Flachsland, Wolfgang Sterk, "Linking carbon markets: concepts, case studies and pathways”, (2009) 9 Climate Policy 341 - 357 at 344 - 345 (“Tuerk at al (2009)”).

65 Sterk 2009 at 426.

${ }^{66}$ Andreas Turk, ETCLIP - The challenge of the European carbon market: emission trading, carbon leakage and instruments to stabilize the CO2 price. Implications of linking on leakage. WIFP Working Paper 410/2011.

${ }^{67}$ On the mechanics of linking see: Michael Mehling and Erik Haites, "Mechanisms for linking emissions trading schemes" (2009) 9.2 Climate Policy 169 and Mace 2008 at chapter 4.
} 
accompanied by a memorandum of understanding or some form of co-operation agreement. ${ }^{68}$ Subnational jurisdictions will not be able to enter into international treaties ${ }^{69}$ and may be constrained from entering into binding agreements by virtue of Constitutional limitations in their powers. In such a case the option of reciprocated unilateral recognition might be considered. There would still be a need for some mutual recognition memorandum ${ }^{70}$ but such an approach should circumvent any Constitutional limitations as well as provide greater flexibility (although less certainty and control). Ultimately with sub-national jurisdictions it will be important to identify the limitations imposed upon them in relation to entering into international agreements, whether any prohibition on creating laws inconsistent with the central government would be infringed and whether there might be a breach of any retention in the central government of a power to legislate in relation to commerce, especially with foreign entities. ${ }^{71}$

In terms of any agreement, the respective jurisdictions are likely to wish to ensure both a level of control and flexibility, especially as to future membership, and an ability to sever the arrangement with a minimum of market disruption. Greater formality should provide less scope for uncertainty. Nevertheless, some uncertainty is inevitable and given the potential adverse impact on markets it could be expected that quantity restrictions might be imposed on the use of the other scheme's allowances with these restrictions gradually loosened as areas of uncertainty are resolved. Some supervisory mechanism to oversee the operation of the linked scheme and adjudicate over differences might be necessary. It may be prudent for the mechanism to require all changes to one ETS to be considered and approved by a body comprising representatives from each jurisdiction affected. Such a supranational mechanism might range from a loose cooperation between linked jurisdictions to an international organization endowed with formal powers, with the later likely to evolve over time. ${ }^{72}$

In addition to the legal framework, the accounting and physical framework will need to be devised. Linkage of the two registries electronically would be expected. Identification of the eligible allowances may require some adjustment mechanism for the different rights attached to each.

Ultimately, it could be expected that some harmonization could be anticipated. In fact, the establishment of procedures to effect the linkage, such as notification and exchange of information procedures and processes for agreeing revisions and resolving disputes might blur the lines between the mere link of separate schemes and the creation of a single larger scheme.

Finally, any linkage agreement must also be forged in recognition of the general agreements on tariffs and trade ("GATT”) and on trade in services (“GATS”). These agreements seek to facilitate free and transparent international trade and, in particular, prohibit discrimination on the basis of country or origin. It is conceivable that a linking agreement might raise an issue of discrimination, in particular by the recognition or refusal to recognize the emissions allowances of, or link with, a particular third country or otherwise placing restrictions on the trade in emissions allowances. An initial issue would be whether

\footnotetext{
${ }^{68}$ If possible any agreement should be established as a multi-lateral agreement or at least provide for the addition of future linkage partners in the expectation that additional linkage opportunities will arise in the future.

${ }^{69}$ Mace 2008 at paragraph 4.1.1.

${ }^{70}$ See Mace 2008 at paragraph 4.3.2 for the possible elements of such a memorandum.

${ }^{71}$ Mace 2008 at paragraph 5.3.

${ }^{72}$ Michael Mehling, "Linking emissions trading schemes” in David Freestone and Charlotte Streck (editors) Legal Aspects of Carbon Trading, Oxford University Press 2009 (“Mehling 2009”) at pages 122 - 124.
} 
emissions allowances even fall within the international agreements. There is a strong case that they are neither products nor services within the meaning of the GATT and GATS. ${ }^{73}$ In any event, measures implemented through a linkage agreement might be exempted as measures designed to protect the environment and hence "human, animal, or plant life or health". ${ }^{74}$

\subsection{Conclusion}

Differences in design features of domestic ETSs are inevitable in the absence of a global standard, and, even then, local political considerations are likely to influence ETS design. Whilst these differences may generate competitive distortions between jurisdictions, few are such as to deny the ability to link regimes. Linkage may require adjustments at the margins to the domestic regimes and so is likely to lead to a degree of harmonization. Furthermore, the ability to change a national system in the future would then need to accommodate the interests of linked partners.

Thus an issue for each jurisdiction is whether the surrendering of some sovereignty in relation to the freedom to design and modify their ETS is outweighed by the benefits from linkage. These benefits include greater market efficiency, more liquidity, enhanced abatement opportunities and, potentially, lower compliance costs. ${ }^{75} \mathrm{~A}$ further consideration will be whether linking with a foreign regime will undermine the environmental effectiveness of the domestic regime to an unacceptable level. Domestic considerations, such as the likely effect on the carbon price of linking and its impact on business and the acceptability of the proposed linkage partner from a political perspective, are also relevant. The later might be a particular issue where (free) allowance allocation decisions in the other country provide competitive advantages over domestic businesses.

For any government considering linking these are all questions of degree and tradeoff - a political decision as to whether the disadvantages and costs of achieving the link will outweigh the benefits on offer. Ultimately the issue is likely to come down to whether both regimes are perceived to share a similar level of ambition in terms of environmental objectives. Linking will almost always be achievable from a legal perspective by employing technical "fixes" if necessary. ${ }^{76}$

To illustrate by way of conclusion, consider the current Australian ETS assuming the former Government's proposals implemented. In considering a potential linkage partner for this regime the first step would be to compare the features of the ETS with that of the foreign jurisdiction. A template could be constructed that identifies the Australian ETS characteristics relevant to linkage and orders them with respect to their significance. The features of the foreign regime under consideration could be inputted.

\footnotetext{
${ }^{73}$ Mace 2008 at paragraph 5.2.1.

${ }^{74}$ GATT Article XX and GATS Article XIV. It has also been argued that an ETS that allocates allowances at no cost under the grandfathering method or does not enforce the terms under which allowances are granted would not breach the Agreement on Subsidies and Countervailing Measures ("SCM agreement"), although the issue is not free from doubt: Mace 2008 at paragraph 5.2.4. Mehling also concludes that the free trade rules are unlikely to constrain linkages: Mehling 2009 at page 128.

${ }^{75}$ In ETS terms, compliance costs include both the direct cost of complying with emissions obligations and the transaction costs imposed on market participants. Thus, where gateway or other forms of cross border adjustments need to be implemented greater transactional compliance costs are conceivable.

${ }^{76}$ Although different rules as to the recognition of allowances may not be "fixable" as ultimately this is seen as a political issue: OECD 2004 at paragraph 2.2.
} 
Aspects identified in the foregoing discussion as potential barriers to linkage could then be identified. Such a template is attached with the features of the Australian regime that are most likely to be impediments to linkage highlighted. ${ }^{77}$ The final step would be to identify what "fixes" and/or compromises might be politically acceptable.

\footnotetext{
${ }^{77}$ Depending on the specifics of the foreign regime other features may also raise difficulties.
} 
Table 1 - Template comparing the design features of the Australian and foreign ETSs from a linkage perspective

\begin{tabular}{|c|c|c|}
\hline Design Feature & Australian ETS (from 1 July & Foreign ETS \\
& 2018) & \\
\hline
\end{tabular}

ESSENTIAL

\begin{tabular}{|l|l|l|}
\hline Type of target & Absolute & \\
\hline Ex-post adjustment & Not proposed. & \\
\hline $\begin{array}{l}\text { Price cap and/or market } \\
\text { intervention } \\
\text { (cost containment) measures }\end{array}$ & $\begin{array}{l}\text { Price cap at AUD\$20 above } \\
\text { expected EU carbon price for } \\
\text { 2014/15 until 2018. No other } \\
\text { intervention measures. }\end{array}$ & \\
\hline Borrowing & Up to 5\%. & \\
\hline Continuance & Ongoing & \\
\hline
\end{tabular}

NEEDED FOR POLITICAL AGREEMENT

\begin{tabular}{|l|l|l|}
\hline Banking & Unlimited & \\
\hline Commitment periods & $\begin{array}{l}\text { Annual - specified five years in } \\
\text { advance. }\end{array}$ & \\
\hline Target stringency & $\begin{array}{l}\text { Not currently specified. } \\
\text { Currently trade exposed } \\
\text { industries receive substantial } \\
\text { concessions in the form of free } \\
\text { units. }\end{array}$ & \\
\hline Limits on foreign allowances & $\begin{array}{l}50 \% \text { foreign (100\% from 2020) } \\
12.5 \% \text { Kyoto units sub-limit. }\end{array}$ & \\
\hline Other domestic offsets/credits & Carbon farming initiative & \\
\hline $\begin{array}{l}\text { Level of compulsion, } \\
\text { governance and enforcement }\end{array}$ & $\begin{array}{l}\text { Mandatory (Clean Energy } \\
\text { Regulator (“CER”)) }\end{array}$ & \\
\hline
\end{tabular}


MAY DIFFER WHERE EQUALLY STRINGENT

\begin{tabular}{|l|l|l|}
\hline Compliance (trading) period & Annual (1 July - 30 June) & \\
\hline Sanctions for shortfalls & $\begin{array}{l}\text { 200\% of the average price of units } \\
\text { for the year. }\end{array}$ & \\
\hline $\begin{array}{l}\text { Monitoring, verification and } \\
\text { reporting }\end{array}$ & $\begin{array}{l}\text { Reports of large emitters (125,000 } \\
\text { tonnes p.a.) must be audited. } \\
\text { Other audits by the CER possible. }\end{array}$ & \\
\hline Leakage control & $\begin{array}{l}\text { Trade exposed industries receive } \\
\text { concessions (currently due to } \\
\text { expire in 2014). }\end{array}$ & \\
\hline
\end{tabular}

\section{DESIRABLE BUT NOT}

ESSENTIAL

\begin{tabular}{|l|l|l|}
\hline Level of application & Upstream (large emitters) & \\
\hline Sector and gas coverage & $\begin{array}{l}\text { Large emitters in most sectors } \\
\text { nationwide. Four types of gases } \\
\text { covered (60\% of Australia's } \\
\text { greenhouse gas emissions). }\end{array}$ & \\
\hline Allocation of allowances & Auction & \\
\hline $\begin{array}{l}\text { New entrants and business } \\
\text { closure }\end{array}$ & $\begin{array}{l}\text { General structure accommodates } \\
\text { most issues. }\end{array}$ & \\
\hline Registries and trading & $\begin{array}{l}\text { Online registry maintained by the } \\
\text { CER. Units tradeable by account } \\
\text { holders once acquired. Auctions } \\
\text { by the CER expected to set price } \\
\text { signal. Units measured in per } \\
\text { tonne of CO } 2 .\end{array}$ & \\
\hline
\end{tabular}

\section{OTHER}

\begin{tabular}{|l|l|l|}
\hline $\begin{array}{l}\text { Kyoto Protocol (allowances } \\
\text { shadowed by Kyoto units - ie. } \\
\text { convertible to ERUs) }\end{array}$ & Unspecified. & \\
\hline Existing linkage partners & $\begin{array}{l}\text { Full linkage with EU planned for } \\
1 \text { July } 2018 .\end{array}$ & \\
\hline
\end{tabular}


